\title{
Efeito do desmatamento na atividade dos microorganismos de solo de terra firme na Amazonia (*)
}

\author{
Osvaldo Manuel Santos (') \\ Breno Machado Crisi $\left({ }^{2}\right)$
}

\section{Resumo}

Estudo realizado em ecossistema de floresta tropical equatorial da Amazônia, em solo de terra-firme, no $\mathrm{Km} 30$ da Rodovia Manaus-Itacoatiara. A firialidade do trabalho foi avaliar o efeito do desmatamento na atividade dos microorganismos do solo. Foram delimitadas três áreas contíguas: uma de floresta primária, outra com vegetação secundária (capoeira) desenvolvida após a derrubada e queima da floresta primária e a terceira com vegetação secundária (capoeira) desenvolvida após a derrubada da floresta primária. O solo do local é um latossolo amarelo e o clima caracteriase por elevadas temperaturas e precipitação pluvial durante a maior parte do ano. A atividade dos microorganismos do solo foi avaliada através de mediçōes da resiração edáfica e de taxa de decomposição da celulose. A respiração edáfica e a taxa de decomposição da celulose decrescem na seguinte ordem: capoeira desenvolvida após derrubada e queima da floresta primária $(C D Q)>$ capoeira desenvolvida após derrubada da floresta primária $(C D)>$ floresta primária $(F P)$. É discutida a influência do manejo de solos sobre a atividade dos microorganismos do solo sobre a produção de cultivos.

\section{INTRODUÇÃo}

A dinâmica de ciclagem de nutrientes num sistema ecológico natural é de vital importância para a sua manutenção, principalmente em ecossistemas estabelecidos sobre solos pobres, como os oxissolos situados nos trópicos úmidos. A eficiência na rapidez, com que os nutrientes passam do meio abiótico para o biótico e deste, através do processo de decomposição da matéria orgânica, de volta para o primeiro, é imprescindível à manutenção de ecossistemas como o da Amazônia.

$\mathrm{O}$ processo de biogeociclagem, portanto, em solo de terra firme na floresta amazônica, propicia um equilíbrio dinâmico, em que são garantidas sua organização estrutural e uma contínua evolução na diversidade de seus componentes peculiares à sua fitofisionomia de ecossistema tropical.

Sendo a matéria orgânica no solo um dos principais responsáveis pelo potencial de nutrientes disponíveis para as plantas da floresta amazônica, um estudo sobre decomposição e mineralização da serrapilheira (ou "litter"), é de grande importância para a compreensão do processo de fertilização natural dos solos. Conseqüentemente, de solos originariamente pobres, poderão extrair-se benefícios para o homem através do aperfeiçoamento de práticas ligadas ao manejo desses solos.

A atividade dos microorganismos do solo é indicador ecológico da ciclagem de nutrientes, visto que, quanto mais elevada for a atividade dos microorganismos do solo, maiores serão a liberação de nutrientes para as plantas e a mineralização da matéria orgânica em decomposição. O metabolismo dos microorganismos do solo é, portanto, um parâmetro indicador da dinâmica de ciclagem da matéria.

No presente trabalho, com a finalidade de avaliar os efeitos do desmatamento sobre a atividade dos microorganismos do solo, foi realizado um estudo comparativo envolvendo determinações da respiração edáfica e da taxa de desomposição da celulose num trecho da floresta primária amazônica em terra firme (FP) e em áreas com vegetação secundária desenvolvidas após a derrubada (CD) e derrubada e queima da floresta primária (CDQ).

(") - Trabalho desenvolvido com auxílio do Conselho Nacional de Desenvolvimento Científico e Tecnológico (CNPq).

(1) - Divisão de Botânica, CEPEC/CEPLAC.

(2) - Departamento de Biologia, Universidade Federal da Paraíba. 


\section{MATERIAIS E MÉTODOS}

\section{O AMBIENTE ESTUDADO}

Este trabalho foi realizado na área do Pro grama dos Trópicos Úmidos (P.T.U.), localizada no $\mathrm{km} 30$ da Rodovia Manaus-Itacoatiara, na latitude $3^{\circ} 8^{\prime} \mathrm{S}$ e longitude $59^{\circ} 52^{\prime} \mathrm{W}$ de Greenwich e a uma altitude de $50 \mathrm{~m}$ acima do nível do mar.

O solo do local estudado, segundo dados do Instituto de Pesquisas e Experimentação Agropecuária do Norte, IPEAN (1969), é classificado como latossolo amarelo, textura muito pesada, profundo, fortemente desgastado, de muito forte a excessivamente ácido, bem drenado, com teor de argila sempre acima de $70 \%$ no horizonte $B$; perfil bem desenvolvido, cor amarela com dominância do matiz 10 YR. Ainda de acordo com o trabalho citado, o solo tem potencialidade natural muito baixa, evidenciada pelos baixos teores de saturaçãc de bases e soma de bases permutáveis muito baixa, devendo-se este fato principalmente ao seu material formador, constituído de sedimentos cauliníticos pobres, do terciário.

O clima é quente e úmido, tipo $\mathrm{Am}$ da classificação de Köppen. A média anual de temperatura é de $26,7^{\circ} \mathrm{C}$; a temperatura máxima do mês mais quente é de $38^{\circ} \mathrm{C}$, sento de $27,7^{\circ} \mathrm{C}$ a média das temperaturas máximas; a temperatura mínima do mês mais frio é de $16,9^{\circ} \mathrm{C}$ e a média das temperaturas mínimas é de $19,7^{\circ} \mathrm{C}$. A média anual de precipitacão é de $1.650 \mathrm{~mm}$. Esses dados climáticos referem-se a observações de quatro anos (1973 a 1976), fornecidos pela Estação Meteoro-agrária da EMBRAPA (Empresa Brasileira de Pesquisa Agro-Pecuária), instalada a aproximadamente $600 \mathrm{~m}$ do local do presente estudo. O diagrama climático, representado na Fig. 1 e elaborado de acordo com Walter (1963), mostra que o clima da região é úmido (área hachuriada do diagrama), com um período super-úmido (área em negrito) caracterizado pela ocorrência de precipitação superiores a $100 \mathrm{~mm}$. No período com precipitações inferiores a $100 \mathrm{~mm}$, há registro de seca (área pontilhada). Foram realizadas medições de temperatura do solo, concomitantes às mediçōes đe respiração edáfica, através de termógrafos de marca Grant Instruments Development Ltda. (Inglaterra), instalados nas áreas estudadas.

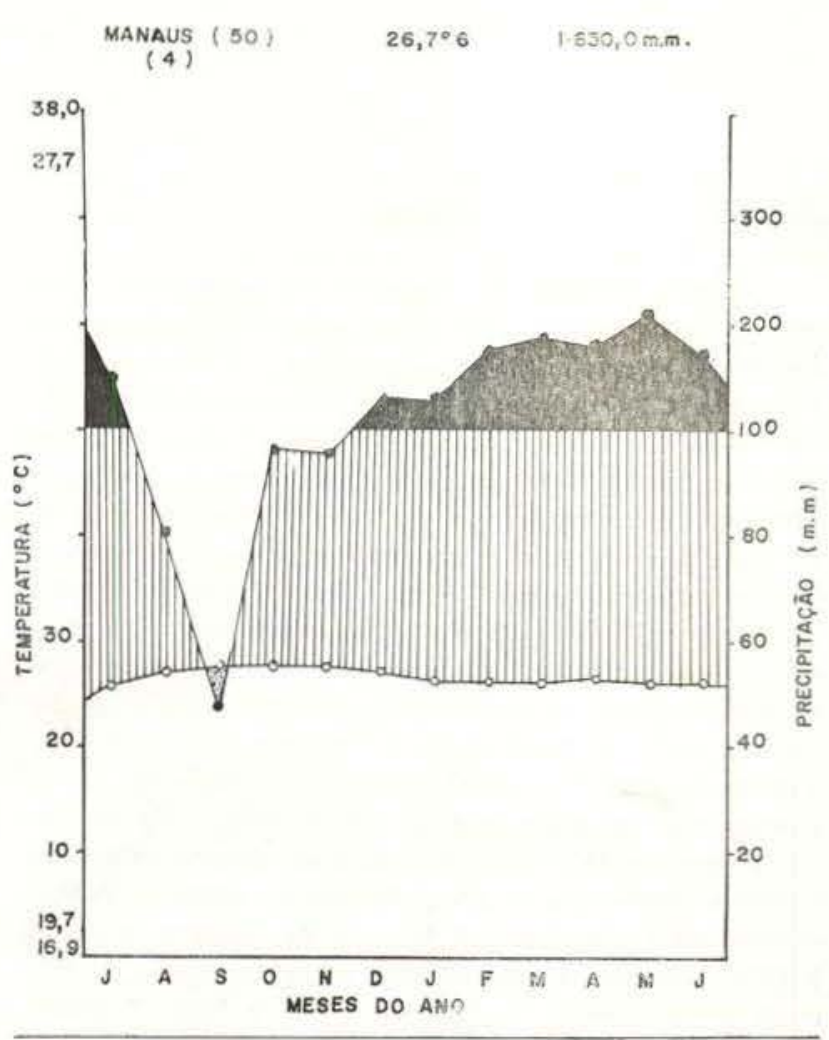

Fig. 1 - Diagrama climático representativo de Manaus, de um período de 4 anos de observações da Estação Meteoro-agrária da EMBRAPA.

A vegetação estudada é típica da Floresta Latifoliada Tropical Equatorial, da classificação de Romariz (1972), estabelecida sobre solo de terra firme, na Amazônia. Após o desmatamento da floresta primária, estabelece-se uma vegetação secundária, denominada "capoeira". Na área onde a vegetação primária foi derrubada e queimada, a "capoeira" apresentava-se um pouco mais desenvolvida em altura e com maior densidade de plantas do que na área onde tinha sido efetuada apenas a derrubada da vegetação primária. Ambas as "capoeiras" encontravam-se com 1 ano e 4 meses de estabelecimento.

Foram delimitadas as áreas para estudo. com 0,50 ha cada, na floresta primária e nas duas "capoeiras", em 5 setores com 5 repetições. 
MEDIÇÃO DA RESPIRAÇÃO EDÁFICA

O método utilizado para medir a respiração edáfica baseia-se na absorção do $\mathrm{CO}_{2}$ emanado do solo por uma solução de $\mathrm{KOH} 0,5 \mathrm{~N}$ e sua dosagem por titulação com $\mathrm{HCl} 0,1 \mathrm{~N}$, método este desenvolvido por Walter \& Haber (1957). Vários autores o têm utilizádo em diversos tipos de ecossistemas (Witkamp, 1966a, b; Medina, 1969; Wanner, 1970; Coutinho \& Lamberti, 1971; Medina \& Zelwer, 1972; Edwards \& Sollins, 1973; Grisi, 1976; Santos, 1977 e outros).

Para a medição da respiração no campo, foram utilizados tubos de PVC rígido, no preparo dos "cilindros invertidos" (Grisi, 1978; Santos, 1977).

Foram realizadas medições de respiração edáfica total (microorganismos mais raízes) e de microorganismos isoladamente (Grisi, 1976, 1978). Todas as medições foram feitas no campo, com 12 horas de exposição para cada período (diurno e noturno). Foram coletadas amostras simultâneas das 3 áreas estudadas. As medições foram realizadas do dia 02 ao dia 05 de março de 1977.

DETERMINAÇÃO DA TAXA DE DECOMPOSIÇÃO DA CELULOSE

$\mathrm{Na}$ avaliação da decomposição da celulose, foi utilizado o método de Unger, descrito por Steubing (1973). Foram colocadas amostras de celulose pura (algodão), com dimensões de $4,0 \mathrm{~cm} \times 4,0 \mathrm{~cm}$ e $1,0 \mathrm{~g}$ de peso seco (Grisi, 1976), em sacos preparados com redes de "nylon" de diferentes aberturas de malhas $(1,0 \mathrm{~mm}$ e $0,03 \mathrm{~mm})$. As amostras foram deixadas enterradas em diferentes profundidades do solo $(0-5 \mathrm{~cm}, 5-15 \mathrm{~cm}$ e $15-30 \mathrm{~cm})$ durante 90 dias (de 1..$^{\circ}$ de março a 29 de maio de 1977). Após esse período, as amostras foram retiradas do solo, lavadas cuidadosamente e depois de secas em estufa a $60^{\circ} \mathrm{C}$, durante 48 horas, foram pesadas para determinar-se a percentagem de perda de seu peso seco inicial.

\section{RESULTADOS}

CONDIÇÕES AMBIENTAIS MICROCLIMÁTICAS

Durante a realização das medições de respiração edáfica, foram determinados os valores de temperatura do ar a 1,0 m acima da superfície do solo e os de temperatura do solo nas profundidades de $2,0 \mathrm{~cm}, 10,0 \mathrm{~cm}$ e 30,0 $\mathrm{cm}$. Os resultados, apresentados na Fig. 2, mostram que há variações, no decorrer do dia, na temperatura do ar a $1,0 \mathrm{~m}$ da superfície do solo; à medida que se aprofunda no solo, as variações na temperatura diminuem. Observa-se que às $6: 00 \mathrm{~h}$ a temperatura do solo é ainda superior à do ar. A partir das 8:00 h, a temperatura do ar torna-se superior à do solo. aumentando essa diferença até às 17:00 h, quando então começam a igualar-se. Durante a noite, a temperatura do solo permanece superior à do ar até o início da manhã. Vale ressaltar que a $2,0 \mathrm{~cm}$ e a $10,0 \mathrm{~cm}$ de profundidade no solo, a temperatura na "capoeira" onde a vegetação primária foi queimada é quase sempre um pouco mais elevada do que nas duas outras áreas (Fig. 2).

\section{RESPIRAÇÃO EDÁFICA}

No Quadro I, são apresentados os resultados de respiração edáfica total e de respiração de microorganismos (isoladamente), obtidos nos 3 tratamentos. Os valores de respiração edáfica total e de microorganismos decrescem no seguinte sentido: $C D Q>C D>F P$.

$\mathrm{Na}$ floresta primária, os valores de respiração edáfica total e de microorganismos foram, durante o período noturno, superiores aos do período diurno. Nas "capoeiras" ocorreu o inverso.

\section{DECOMPOSIÇÃO DA CELULOSE}

No Quadro II, figuram os resultados da decomposição da celulose, representativos de um período de 90 dias. Tais resultados corroboram o observado através da respiração edáfica ou seja mais freqüentemente ocorre um decréscimo na atividade dos microorganismos. 

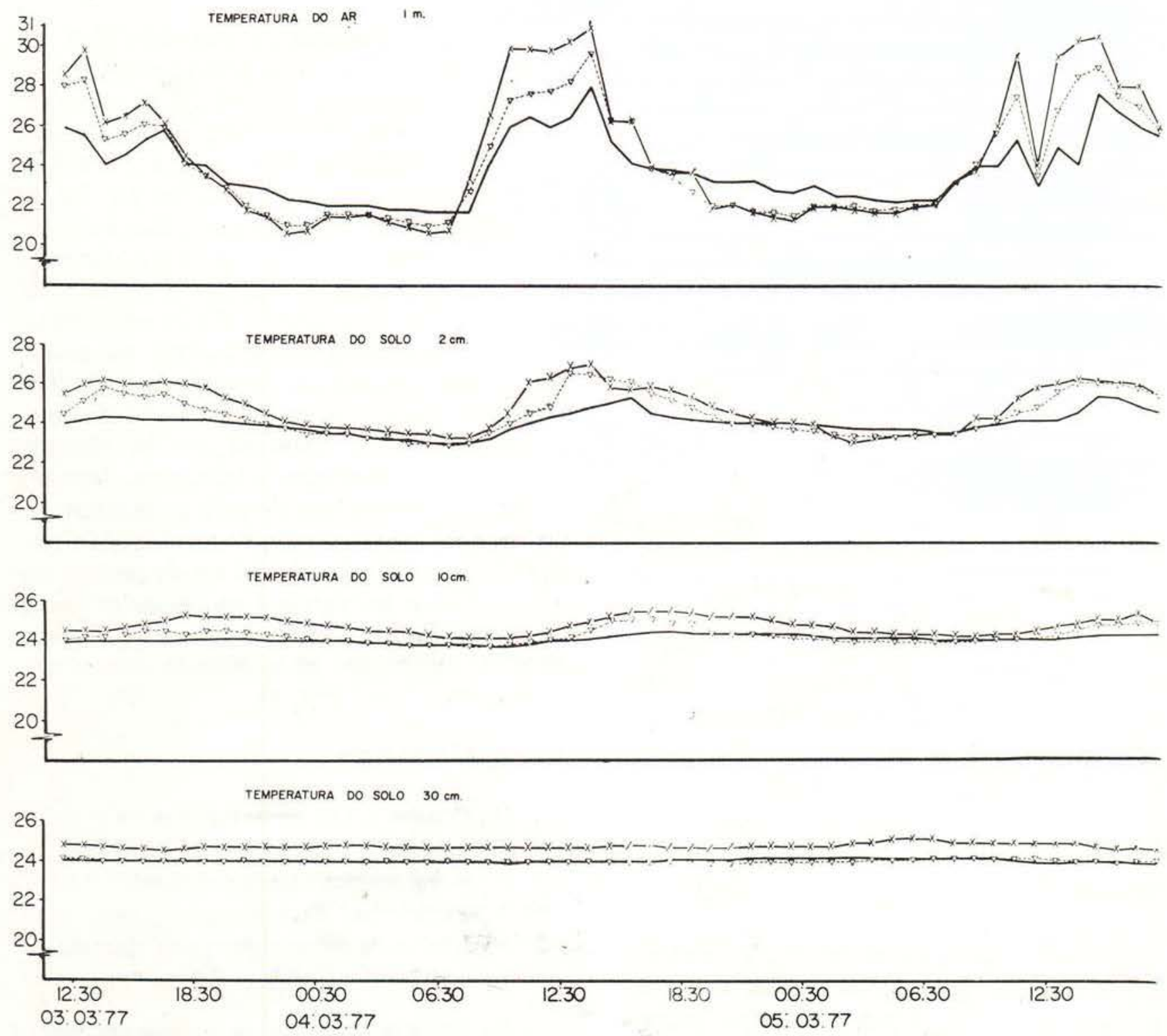

Fig. 2 - Gráficos representativos do andamento diário das temperaturas do ar a $1 \mathrm{~m}$ acima do solo e do solo nas profundidades de $2 \mathrm{~cm}, 10 \mathrm{~cm}$ e $30 \mathrm{~cm}$.

responsáveis pela decomposição da celulose, no seguinte sentido: $C D Q>C D>F P$.

A taxa de decomposição decresce com o aumento da profundidade do solo. Na floresta primária, a decomposição foi mais elevada nas amostras colocadas nos sacos com malha de $0,03 \mathrm{~mm}$. Nas "capoeiras" e principalmente na superfície do solo, a taxa de decomposição da celulose foi mais elevada nos sacos com malha de $1,0 \mathrm{~mm}$, indicando que nesse local, provavelmente, além da participação de microorganismos, há uma atividade mais intensa de determinados invertebrados do solo (com exceção dos vermes) no processo de degradação da matéria orgânica. 
QUADRO 1 - Respiração edáfica de microorganismos + raízes (MR) e de microorganismos isoladamerte (M) em $\mathrm{mg} \cdot \mathrm{CO}_{2} \cdot \mathrm{m}^{-2} \cdot \mathrm{h} \cdot{ }^{-1}$. e percentagem de participa ção de microorganismos na respiração edáfica total após derrubada da floresta primária, em Manaus, no período de 02 a 05/03/77.

\begin{tabular}{|c|c|c|c|c|c|c|c|c|c|}
\hline \multirow{3}{*}{ Período } & \multicolumn{3}{|c|}{ Floresta Primária } & \multicolumn{3}{|c|}{ "Capoeira" Após Derrubada } & \multicolumn{3}{|c|}{$\begin{array}{c}\text { "Capoeira" Após Derrubada } \\
\text { e Queima }\end{array}$} \\
\hline & \multicolumn{2}{|c|}{$\mathrm{mg} \cdot \mathrm{CO}_{2} \cdot \mathrm{m}^{-2} \cdot \mathrm{h} \cdot$} & \multirow[t]{2}{*}{$\%$} & \multicolumn{2}{|c|}{$\mathrm{mg} \cdot \mathrm{CO}_{2} \cdot \mathrm{m}^{-2} \mathrm{~h}^{-1}$} & \multirow{2}{*}{$\%$} & \multicolumn{2}{|c|}{$\mathrm{mg} \cdot \mathrm{CO}_{2} \cdot \mathrm{m}^{-2} \cdot \mathrm{h}-1$} & \multirow[t]{2}{*}{$\%$} \\
\hline & MR & $M$ & & MR & $M$ & & MR & $M$ & \\
\hline Noturno & 449,25 & 247,12 & 55,00 & 517,63 & 237,92 & 45,96 & 639,15 & 343,13 & 53,68 \\
\hline Diurno & 408,11 & 202,29 & 49,57 & 526,70 & 265,51 & 50,41 & 664,18 & 352,23 & 53,03 \\
\hline Média & 428,68 & 224,70 & 52,42 & 522,16 & 251,71 & 48,20 & & 347,68 & 53,35 \\
\hline
\end{tabular}

QUADRO 2 - Taxa de decomposição da celulose, em solo de terra-firme da floresta amazônica, durante um período de 90 dias $(30.03 .77$ a 03.06 .77$)$.

\begin{tabular}{|c|c|c|c|c|c|c|c|}
\hline \multirow{3}{*}{\multicolumn{2}{|c|}{$\begin{array}{l}\text { Profundidade } \\
\text { do Solo }(\mathrm{cm})\end{array}$}} & \multicolumn{4}{|c|}{ PERDA DE PESO SECO } & & \\
\hline & & \multicolumn{2}{|c|}{ Floresta Primária } & \multicolumn{2}{|c|}{$\begin{array}{l}\text { "Capoeira" Após } \\
\text { Derrubada e Queima* }\end{array}$} & \multicolumn{2}{|c|}{$\begin{array}{l}\text { "Capoeira" Após } \\
\text { Derrubada }\end{array}$} \\
\hline & & $\mathrm{mg}^{* *}$ & $\%$ & $\mathrm{mg}^{* *}$ & $\%$ & mg** & $\%$ \\
\hline \multirow{2}{*}{0.5} & Malha $1.0 \mathrm{~mm}$ & 0,4864 & 48,64 & 0,5473 & 54,73 & 0,5168 & 51,68 \\
\hline & Malha $0,03 \mathrm{~mm}$ & 0,5485 & 54,85 & 0,3867 & 38,67 & 0,4813 & 48,13 \\
\hline \multirow{2}{*}{$5-15$} & Malha $1,0 \mathrm{~mm}$ & 0,1588 & 15,88 & 0,5329 & 53,29 & 0,2077 & 20,77 \\
\hline & Malha $0,03 \mathrm{~mm}$ & 0,2692 & 26,92 & 0,3699 & 36,99 & 0,3088 & 30,88 \\
\hline \multirow{2}{*}{$15-30$} & Malha $1,0 \mathrm{~mm}$ & 0,1182 & 11,82 & 0,1148 & 11,48 & 0,1625 & 16,25 \\
\hline & Malha $0,03 \mathrm{~mm}$ & 0,1853 & 18,53 & 0,3030 & 30,30 & 0,1101 & 71,01 \\
\hline
\end{tabular}

(:) O processo de queima fol feito como o comumente usado na regiāo, com e sem encoivaramento.

(*) Quantidade decomposta a partir de $1 \mathrm{~g}$ de celulose (peso seco inicial).

\section{DISCUSSÃO E CONCLUSÕES}

Dos resultados obtidos pode notar-se a influência do desmatamento na atividade dos microorganismos do solo. A vegetação secundária das "capoeiras" apresentam valores mais elevados nas taxas de respiração edáfica total. As raízes contribuem com quase $50 \%$, cabendo o restante aos organismos do solo. A queima, em especial, parece exercer, pelo menos nos primeiros anos de desenvolvimento da vegetação secundária, uma ação benéfica sobre a atividade dos microorganismos do solo, devendo-se este fato provavelmente a mu- danças nas propriedades edáficas, ocorridas após a ação do fogo sobre a fitomassa. Isto também tem sido observado por Santos (1977). Santos \& Grisi (1978) e Grisi \& Santos (1978) em ecossistemas de floresta no sul da Bahia. Tanto a respiração edáfica como a taxa de decomposição da celulose demonstram haver tal influência de queima no metabolismo dos microorganismos do solo.

Este aumento na atividade dos microorganismos do solo, após a queima, representará uma mobilização dos nutrientes retidos na biomassa, com perdas enormes e irrecuperáveis. Face a este aumento da respiração microbiana, 
pode estimar-se que $50 \%$ da matéria orgânica do solo será destruída no $1 .^{\circ}$ ano e $30 \%$ no $2 .^{\circ}$ ano, após a queima. Nos solos de terra firme da Amazônia, os resultados serão negativos a médio prazo, como aliás, vem sendo verificado na prática.

\section{SUMMARY}

This study was carried out at $\mathrm{Km} 30$ on the Manaus-Itacoatiara highway, in the state of Amazonas, Brazil, with the purpose of evaluating microorganism activity in three adjacent areas: undisturbed primary forest; secondary forest developed after clearing and burning: and secondary forest developed after clearing only.

The area studied is an equatorial humid forest, with the soil classified as oxisol. The annual mean temperature is $26.7^{\circ} \mathrm{C}$ and annual mean precipitation is $1.650 \mathrm{~mm}$, with drought in september.

Microorganism activity was measured by soil respiration with the "inverted box" method, and the "cotton buried" method determined the rate of cellulose decomposition.

The secondary forest developed after claring and burning had higher microorganism activity than the secondary forest developed after clearing cnly. The undisturbed primary forest had the least microorganism activity.

In this paper the influence of soil management on the activity of soil microorganism and on crop production is discussed.

\section{REFERÊNCIAS BIBLIOGRÁFICAS}

COUTINHO, L.M. \& LAMBERTI, A.

1971 - Respiração edáfica e produtividade primária numa comunidade amazônica de mata de terra firme. Ciência e Cultura, 23 (3): 411-419.

EDWARDS, N.T. \& SOLLINS, P.

1973 - Continuous measurement of carbon dioxide evolution from partitioned forest floor components. Ecology, 54 (2): 406-412.

GRISI, B.M.

1976 - Biodinâmica de solo cultivado com cacaueiros sombreados e ao sol. Revista Theobroma, 6 (4): 87-99.

1978 - Método químico de medição da respiração edáfica: alguns aspectos técnicos. Ciência e Cultura, 30 (1): 82-88.

GRISI, B.M. \& SANTOS, O.M.

1978 - Respiraçăo edáfica em vegetação natural e submetida à queima, num ecossistema de Floresta Tropical no Sul da Bahia. Revista Brasileira de Biologia, 38 (3) (no prelo).
IPEAN

1969 - Os solos da área Manaus-Itacoatiara. Edição do Setor de Relações Públicas, 116 p. Série Estudos e Ensaios, n. 1.

MEDINA, E.

1969 - Respiración edáfica de algumas comunidades tropicales. Bol. Sociedad Venezoelana Cien. Naturales, $28(115 / 116) \cdot 211-230$.

MEdina, E. \& ZELWER, M.

1972 - Soil respiration in tropical plants communities. Proc. IInd. Int. Sym. Tropicla Ecology, Athens, Georgia. F. Golley (ed.) p. 245246

ROMARIZ, D.A.

1972 - A vegetação. IN: Brasil e terra e o homem. Aroldo de Azevedo (ed.) 20 ed. Cia. Edt. Nacional, Săo Paulo, p. 521-572.

SANTOS, O.M.

1977 - Biodinâmica de um ecossistema de solo de "tabuleiro" da região sul da Bahia. Universidade Federal da Bahia, Salvador. Tese de Nestrado, mimeografada. $87 \mathrm{p}$.

SANTOS, O.M. \& GRISI, B.M.

1978 - Decomposição da matéria orgânica em solo de floresta tropical no sul da Bahia. Estudo comparativo em áreas queimada e não queimada. Revista Brasileira de Ciência do Solo (no prelo)

Steubing, L.

1973 - Soil flora: studies of the number and activity of microorganisms in woodland soils. IN: Analysis of temperate forest Ecosystems. D.E. Reichle (ed) Springer-Verlag. Berlin p. 131-146.

WALTER, $\mathrm{H}$.

1963 - Climatic diagrams as a mean to comprehend various climatic types for ecological and agricultural purposes. In: The Water Relations of Plants. Blackwell Scientific Publications, London. p. 3-9

WALTER, H. \& HABER, W.

1957 - Uber die intensitat der Bodenatnung nuit beuerkingen zu den lundegardoschen werten. Botanischen Gesellschaft, 70: 275-282.

WANNER, $\mathrm{H}$.

1970 - Soil respiration litter fall and productivity of tropical rain forest. J. Ecology, 58: 543 548

WITKAMP, M.

1966a - Decomposition of leaf litter in relation to environment, microflora and microbial respiration. Ecology, 47 (2): 194-201.

$1966 \mathrm{~b}$ - Rates of carbon dioxide evolution from the forest floor. Ecology, 47 (3): 492-494.

(Aceito para publicação em 20/09/80) 